\title{
Chemical characterization and antioxidant activity of sulfated polysaccharide from the red seaweed Gracilaria birdiae
}

\author{
Bartolomeu W.S. Souza ${ }^{\mathrm{a}, \mathrm{c}}$, Miguel A. Cerqueira ${ }^{\mathrm{a}}$, Ana I. Bourbon ${ }^{\mathrm{a}}$, Ana C. Pinheiro ${ }^{\mathrm{a}}$, Joana T. Martins ${ }^{\mathrm{a}}$, \\ José A. Teixeira ${ }^{a}$, Manuel A. Coimbra ${ }^{b}$, António A. Vicente ${ }^{\mathrm{a}, *}$ \\ a IBB - Institute for Biotechnology and Bioengineering, Centre of Biological Engineering, Universidade do Minho, Campus de Gualtar, 4710-057 Braga, Portugal \\ ${ }^{\mathrm{b}}$ Departamento de Química, Universidade de Aveiro, 3810-193 Aveiro, Portugal \\ ${ }^{\mathrm{c}}$ Departamento de Engenharia de Pesca, Universidade Federal do Ceará, Fortaleza - Ceará, Brazil
}

\section{A R T I C L E I N F O}

\section{Article history:}

Received 8 July 2010

Accepted 5 October 2011

\section{Keywords:}

Gracilaria

Sulfated polysaccharide

Antioxidant activity

\begin{abstract}
A B S T R A C T
Hydrocolloids from seaweeds have interesting functional properties, such as antioxidant activity and gelling ability. A polysaccharide was isolated by aqueous extraction at $90{ }^{\circ} \mathrm{C}$ from the red seaweed Gracilaria birdiae $(G b)$, with a yield of $27.2 \%$ of the seaweed dry weight. The sulfate content of the polysaccharide was $8.4 \%$ and the main sugars present were galactose $(65.4 \mathrm{~mol} \%), 3,6$-anhydrogalactose (25.1 mol\%) and 6-O-methylgalactose (9.2 mol\%). Gel permeation chromatography showed that $G b$ polysaccharide is a heterogeneous system, with molar mass at the main peak of $3.7 \times 10^{5} \mathrm{~g} \mathrm{~mol}^{-1}$ and a shoulder of $2.6 \times 10^{6} \mathrm{~g} \mathrm{~mol}^{-1}$. The sulfated polysaccharide of $G b$ characterized by FTIR exhibits the characteristic bands of agarocolloids (at 1375 and $770 \mathrm{~cm}^{-1}$ ).

The rheological behavior of $G b$ sulfated polysaccharide exhibits a gel-like behavior close to the one observed in commercial agar.

The antioxidant properties of $G b$ sulfated polysaccharide were evaluated by measuring DPPH freeradical scavenging effect, showing that this polysaccharide has a moderate effect in inhibiting the formation of those radicals.
\end{abstract}

(c) 2011 Elsevier Ltd. All rights reserved.

\section{Introduction}

In recent years, marine resources have attracted attention in the search for bioactive compounds to develop new drugs and healthy foods (Qi, Zhao, Zhang, Li, \& Zhao, 2005). In particular, seaweeds are a very important and commercially valuable resource for food, fodder, soil conditioners and pharmaceuticals (Yang et al., 2006). Moreover, sulfated polysaccharides from marine algae are known to exhibit many biological and physiological activities including anticoagulant, antiviral, antitumor, anti-inflammatory and antioxidant (Becker, Guimarães, Mourão, \& Verli, 2007; F-Tischer, Talarico, Noseda, Guimarães, \& Duarte, 2006; Souza et al., 2007; Ye, Wang, Zhou, Liu, \& Zeng, 2008).

Red seaweeds synthesize a great variety of sulfated galactans, which are the major components of the extracellular matrix. Polysaccharides from the Gracilaria genus are composed mainly of the alternating 3-linked- $\beta$-D-galactopyranose unit (Gal) and the 4-linked3,6-anhydro- $\alpha$-L-galactopyranose unit (AnGal). The Gal unit can be substituted by either a methyl or a sulfate ester groups (Rees, 1961).

\footnotetext{
* Corresponding author. Tel.: +351 253 604419; fax: +351 253678986

E-mail address: avicente@deb.uminho.pt (A.A. Vicente).
}

Marine red algae of the genus Gracilaria are a major agarophyte resource in the world and are cultivated for the phytocolloid industry or for integrated marine culture (Troell et al., 2003). The red marine alga Gracilaria birdiae has a great economic impact in Brazil due to agar production (Plastino, Ursi, \& Fujii, 2004). Marinho-Soriano, Moreira, and Carneiro (2006) studied the cultivation of this species in the sea and Maciel et al. (2008) studied the isolation and structural characterization of the cold water-soluble fraction of polysaccharide taken from G. birdiae cultivated on the Atlantic coast of Brazil (Fleixeiras Beach, in the State of Ceará). No studies have yet been performed on the chemical characterization of its polysaccharides extracted with hot water.

When the natural defenses of an organism (of enzymatic, non-enzymatic, or dietary origin) are overwhelmed by an excessive generation of reactive oxygen species (ROS), a situation of 'oxidative stress' occurs. Consequently, cellular and extracellular macromolecules (proteins, lipids, and nucleic acids) can suffer oxidative damage, causing tissue injury (Halliwell \& Auroma, 1991; Halliwell \& Gutteridge, 1989). Most organisms are able to defend themselves from oxidations and repair oxidative damages. However, the innate defense in the human body may not be enough for severe oxidative stress. Antioxidants are substances that can 
delay or prevent oxidation of cellular oxidizable substrates (Wang, Zhang, Zhang, Zhang, \& Li, 2009). Hence, certain amounts of exogenous antioxidants are constantly required to maintain an adequate level of antioxidants in order to balance the amount of ROS (Li, 2007).

In order to reduce damage to the human body and prolong the storage stability of foods, synthetic antioxidants are used for industrial processing. The most commonly used antioxidants at the present time are butylated hydroxyanisole (BHA), butylated hydroxytoluene (BHT), propyl gallate (PG), and tert-butylhydroquinone (TBHQ) (Qi et al., 2005).

In recent years, algal polysaccharides have been demonstrated to play an important role as free-radical scavengers and antioxidants for the prevention of oxidative damage in living organisms (Kim et al., 2007; Souza et al., 2007; Wang et al., 2009). More recently Cerqueira et al. (2009) studied the applicability of sulfated polysaccharide from $G$. birdiae as cheese coatings.

Polysaccharides from seaweeds have also interesting thickening and gelling properties. Since the rheological behavior is directly linked to the structure of the polysaccharide, the rheological characterization of sulfated polysaccharide from G. birdiae is required.

The aim of this work was to obtain sulfated polysaccharides from $\mathrm{G}$. birdiae isolated by aqueous extraction at $90^{\circ} \mathrm{C}$ and evaluate their chemical and rheological properties and to test their antioxidant potential.

\section{Materials and methods}

\subsection{Chemical analyses}

Total sugar content of each fraction was determined according to the method of Dubois, Gillis, Hamilton, Rebers, and Smith (1956). Protein content was measured by Bradford's method (Bradford, 1976).

\subsection{Extraction of polysaccharides}

Specimens of the red seaweed G. birdiae were collected in the Atlantic coast of Brazil (Fleixeiras Beach, Trairi, Ceará). This species grows attached to rocks or dead coral. The diploid phase that develops directly on the female thallus, the carposporophyte, is evident all year in the area, and was selected as seed material. The seedlings were cleaned and then tied in a structure made of string, which was placed in the sea $\left(03^{\circ} 13^{\prime} 25^{\prime \prime} \mathrm{S}\right.$ and $039^{\circ} 16^{\prime} 65^{\prime \prime}$ $\mathrm{W})$, where it was anchored and submerged for two months. After that period algae were collected, cleaned of epiphytes, washed with distilled water and stored at $-20^{\circ} \mathrm{C}$.

The samples were air dried and then milled. The powder was extracted with water $(1.5 \% \mathrm{w} / \mathrm{v})$ at $25{ }^{\circ} \mathrm{C}$ with mechanical stirring for $15 \mathrm{~h}$. The algal residue was removed by filtration and supernatant discarded. The algal residue obtained from the first extraction was extracted with water at $90{ }^{\circ} \mathrm{C}$ with mechanical stirring for $45 \mathrm{~min}$. The residue was removed by centrifugation, and the supernatant was precipitated with ethanol $(1: 3 \mathrm{v} / \mathrm{v})$, lyophilized and stored.

\subsection{Determination of sulfate content in polysaccharides}

Sulfate content in polysaccharides was determined by the barium chloride-gelatin method (Lloyd, Dodgson, Price, \& Rose, 1961). A standard curve was made as follows: $0.02 ; 0.04 ; 0.06$; $0.08 ; 0.10 ; 0.12 ; 0.16 ; 0.18$ and $0.20 \mathrm{~mL} \mathrm{~K}_{2} \mathrm{SO}_{4}$ standard solution $\left(0.6 \mathrm{mg} \mathrm{mL}^{-1}\right)$ were accurately put into test tubes; hydrochloric acid $(1 \mathrm{M})$ was compensated to $0.2 \mathrm{~mL}$ solution. Then $3.8 \mathrm{~mL}$ of trichloroacetic acid ( $3 \% \mathrm{v} / \mathrm{v})$ and $1.0 \mathrm{~mL}$ of barium chloride-gelatin solution ( $5 \mathrm{~g} \mathrm{~L}^{-1}$ ) were added, vortexed, and absorbances were measured at $360 \mathrm{~nm}$ after incubation for $15 \mathrm{~min}$ at room temperature; $0.2 \mathrm{~mL}$ hydrochloric acid solution was used as a blank.

\subsection{Polysaccharide analyses}

The monosaccharide composition of red seaweed galactans was obtained by reductive hydrolysis (Stevenson \& Furneaux, 1991). This technique combines hydrolysis (with $\mathrm{CF}_{3} \mathrm{CO}_{2} \mathrm{H}$ ) and reduction (with 4-methylmorpholine-Borane) followed by acetylation to produce alditol acetates. After acetylation, these alditol acetate derivatives were analyzed by gas chromatography (GC) (Carlo Erba 6000, Carlo Erba, Milan, Italy) with a split injector (split ratio 1:60) and a flame ionization detector. The column was a DB-225 (J \& W, USA) with $30 \mathrm{~m} \times 0.25 \mathrm{~mm}$ and film thickness of $0.25 \mu \mathrm{m}$; the oven temperature program was: $220^{\circ} \mathrm{C}$ during $5 \mathrm{~min}$, being then the temperature raised at a rate of $20^{\circ} \mathrm{C} \mathrm{min}^{-1}$ to $230{ }^{\circ} \mathrm{C}$ and maintained at this temperature for further $6 \mathrm{~min}$. The flow rate of the carrier gas $\left(\mathrm{H}_{2}\right)$ was set at $1 \mathrm{~mL} \mathrm{~min}^{-1}$ at $220^{\circ} \mathrm{C}$. The injector temperature was $220^{\circ} \mathrm{C}$ and the flame ionization detector temperature was $230^{\circ} \mathrm{C}$. The monosaccharide composition was quantified by Gas chromatography-mass spectrometry (GC-MS), the analysis was performed in a HP (USA) series 2 gas chromatograph and Trio-1S VG mass-lab with scans between 400 and $35 \mathrm{~m} / \mathrm{e} / \mathrm{s}$ with a $70 \mathrm{eV}$ ionization energy. All mass spectra were compared with the library data system of the GC-MS equipment (Wiley 275). The hydrolysis of all samples was performed in duplicate and each one was injected twice.

\subsection{Molar mass distribution}

The peak molar masses $\left(M_{\mathrm{pk}}\right)$ were estimated by gel permeation chromatography (GPC) with a Shimadzu equipment at room temperature using an Ultrahydrogel linear column $(7.8 \times 300 \mathrm{~mm}$, exclusion limits $10^{6} \mathrm{~g} \mathrm{~mol}^{-1}$ ), flow $0.5 \mathrm{~mL} \mathrm{~min}^{-1}, 0.5 \%$ polysaccharide concentration and $0.1 \mathrm{M} \mathrm{NaNO}_{3}$ as solvent. A differential refractometer and an ultraviolet photometer (at $280 \mathrm{~nm}$ ) were used as detectors and the elution volume corrected to the internal marker of ethylene glycol at $10.45 \mathrm{~mL}$. Pullulan samples (Shodex Denko) of $M_{\mathrm{w}} 5.9 \times 10^{3}, 1.18 \times 10^{4}, 4.73 \times 10^{4}, 2.12 \times 10^{5}$ and $7.88 \times 10^{5} \mathrm{~g} \mathrm{~mol}^{-1}$ were used as standards.

\subsection{FTIR analysis}

The IR spectra of the polysaccharides were determined using a Fourier transform infrared spectrometer (FTIR) (Perkin-Elmer 16 PC spectrometer, Boston, USA). The polysaccharide was ground with spectroscopic grade potassium bromide $(\mathrm{KBr})$ powder and then pressed into $1 \mathrm{~mm}$ pellets for FTIR measurement in the wavenumber range of 600 and $4000 \mathrm{~cm}^{-1}$ using 16 scans.

\subsection{Rheological measurements}

The measurements under frequency sweep of G. birdiae sulfated polysaccharide and commercial-grade agar (Fluka, Switzerland) have been performed using a controlled - strain rheometer (AR-G2) from TA Instruments (USA), using a plate and plate geometry (diameter: $25 \mathrm{~mm}$ ) with a gap between plates of $1 \mathrm{~mm}$. Frequency sweeps were performed, at $25^{\circ} \mathrm{C}$, in the $0.1-10 \mathrm{~Hz}$ range and the strain was fixed at $0.7 \%$ in order to assure that the working conditions lied in the linear viscoelastic region. In fact, before performing frequency spectra, the linear viscoelastic region was determined and the appropriate strain was selected, by means of 
strain sweeps conducted at different frequencies $(0.1,1$ and $10 \mathrm{~Hz})$ and variable strain ranging from 0.01 to $10 \%$. This type of test determines the maximum deformation attainable for a system without structural failure. Measurements were performed in triplicate.

\subsection{Determination of antioxidant activity}

\subsubsection{Effect of scavenging 1,1-diphenyl-2-picrylhydrazyl (DPPH) radicals}

The free-radical scavenging capacity of the sulfated polysaccharides $(G b)$ was analyzed using the 1,1-diphenyl-2picrylhydrazyl (DPPH) test according to the method of Blois (1958), with some modifications. BHT was used as reference material. Briefly, $0.2 \mathrm{~mL}$ of $\mathrm{MeOH}$ and $0.3 \mathrm{~mL}$ of various sample concentrations $\left(0.1-2.0 \mathrm{mg} \mathrm{mL}^{-1}\right)$ dissolved in $\mathrm{MeOH}$ were mixed in a $10-\mathrm{mL}$ test tube. DPPH $(2.5 \mathrm{~mL}$ of $75 \mu \mathrm{M}$ in $\mathrm{MeOH})$ was then added to achieve a final volume of $3.0 \mathrm{~mL}$. The solution was kept at room temperature for $30 \mathrm{~min}$, and the absorbance at $517 \mathrm{~nm}\left(A_{517}\right)$ was measured.

The DPPH scavenging effect was calculated as follows:

Scavenging effect $(\%)=\left[A_{0}-\left(A-A_{\mathrm{b}}\right) / A_{0}\right] \times 100$

where $A_{0}=A_{517}$ of DPPH without sample; $A=A_{517}$ of sample and $\mathrm{DPPH}$; and $A_{\mathrm{b}}=A_{517}$ of sample without DPPH.

\subsubsection{Hydroxyl radical scavenging activity}

The scavenging activity of seaweed polysaccharides against the hydroxyl radical was investigated using Fenton's reaction $\left(\mathrm{Fe}^{2+}+\mathrm{H}_{2} \mathrm{O}_{2} \rightarrow \mathrm{Fe}^{3+}+\mathrm{OH}^{-}+{ }^{\circ} \mathrm{OH}\right)$. The results were expressed as an inhibition rate. Hydroxyl radicals exhibit a small diffusion capacity and are most reactive in the induction of injuries to cellular molecules and, accordingly, deserve special attention. Hydroxyl radicals were generated using a modified Smirnoff and Cumbes' (1989) method: in $3 \mathrm{~mL}$ sodium phosphate buffer $(150 \mathrm{mM}, \mathrm{pH}$ 7.4), which contained $10 \mathrm{mM} \mathrm{FeSO} \cdot \cdot 7 \mathrm{H}_{2} \mathrm{O}, 10 \mathrm{mM}$ EDTA, $2 \mathrm{mM}$ sodium salicylate, $30 \% \mathrm{H}_{2} \mathrm{O}_{2}(200 \mu \mathrm{L})$ and varying concentrations of polysaccharides $\left(0.1-2.0 \mathrm{mg} \mathrm{mL}^{-1}\right)$. In the control sample, sodium phosphate buffer replaced $\mathrm{H}_{2} \mathrm{O}_{2}$. The solutions were incubated at $37^{\circ} \mathrm{C}$ for $1 \mathrm{~h}$, and the presence of hydroxyl radical was detected by monitoring absorbance at $510 \mathrm{~nm}$.

\subsection{Statistical analyses}

Statistical analyses were performed using Analysis of Variance (ANOVA) and linear regression analysis. The Tukey test $(\alpha=0.05)$ was used to determine any significance of differences between specific means (SigmaStat, trial version, 2003, USA).

\section{Results and discussion}

\subsection{Extraction and chemical analyses}

The milled red seaweed was washed with water at room temperature and the residue left was exhaustively extracted with hot water $\left(90^{\circ} \mathrm{C}\right)$. This method revealed to have a higher yield (27.2\%) than cold extraction (see Table 1). Maciel et al. (2008) studied the structural characterization of cold extracted fraction of sulfated polysaccharide from G. birdiae and showed that the low yield might be due to the low extraction temperature. However the agar yield of Gracilaria cornea from Mexico and from Brazil was found to range from 35.6 to $42.1 \%$ (Freile-Pelegrín \& Robledo, 1997) and from 29 to 41\% (Marinho-Soriano, Silva \& Moreira, 2001), respectively, depending on the season. Melo, Feitosa, Freitas, and de Paula (2002) showed that the temperature is one important factor responsible for the yield of extraction. Armis (1995) showed that in general the yield of extraction of agar from Gracilaria species is very variable due to several factors, such as environmental conditions, seasonal variation, physiological factors and extraction methods. As can be seen in Table 2, the extraction with hot water originated levels of sulfate of $8.4 \%$, higher than those found in the literature for other tropical species of Gracilaria (Cote \& Hanisak, 1986; FreilePelegrin \& Murano, 2005; Marinho-Soriano \& Bourret, 2005), such as $G$. cornea (collected in Mexico), which showed variations from 4.8 to $5.5 \%$. The G. birdiae polysaccharide obtained by cold extraction has a sulfate content (6.4\%) (Maciel et al., 2008) in the range observed for polysaccharides from other Gracilaria species (2.3-8.9\%). However, Mazumder et al. (2002), found levels of sulfate ranging from 2.1 to $11.7 \%$ for fractions of Gracilaria corticata and the higher levels were attributed to fractions obtained from cold extraction. It may thus be concluded that low temperatures are responsible for lower agar extraction yields but they allow higher sulfate concentrations to be attained.

In the present work $G b$ exhibits low levels (2.5\%) of protein content (Table 2), which are in agreement with the values observed in the literature (Melo et al., 2002). Analyses of total sugars by the method of phenol/sulfuric acid according to Dubois et al. (1956), showed high percentages of these compounds (85.6\%).

\subsection{Monosaccharide composition and molar mass distribution}

Table 2 shows the monosaccharide composition of galactans obtained from G. birdiae. The results show that these galactans have a high content of galactose (65.4\%) and 3,6-anhydrogalactose (25.1\%) obtained by reductive hydrolysis and quantified by GC-MS. The methyl derivatives: $6-0$-methylgalactose $(9.2 \%)$ and in smaller quantities $3-0$ - and $4-0$-methyl-galactose $(0.33 \%)$ were also quantified by GC-MS. The presence of galactose and 3,6anhydrogalactose as major monosaccharides has been observed

Table 1

Yield of extraction of agarans obtained from different species of Gracilaria.

\begin{tabular}{|c|c|c|c|c|}
\hline Species & Local & Type of extraction & Yield of extraction (\%) ${ }^{\mathrm{a}}$ & Reference \\
\hline G. birdiae & Brazil & Hot extraction & 27.2 & Present work \\
\hline G. birdiae & Brazil & Room temperature & 6.5 & Maciel et al., 2008 \\
\hline G. bursa-pastoris & France & Autoclaving & 34.8 & Marinho-Soriano, 2001 \\
\hline G. cervicornis & Brazil & Hot extraction & $11.0-20.0$ & Marinho-Soriano, Silva, \& Moreira, 2001 \\
\hline G. cervicornis & Mexico & Hot extraction & $25.0-39.3$ & Freile-Pelegrın \& Murano, 2005 \\
\hline G. cornea & Brazil & Enzymatic digestion & $11.0-21.4$ & Melo et al., 2002 \\
\hline G. dura & France & Autoclaving & 33.5 & Marinho-Soriano, 2001 \\
\hline G. gracilis & France & Autoclaving & $11.1-18.7$ & Mollet, Rahaoui, \& Lemoine, 1998 \\
\hline
\end{tabular}

a Percentages based on milled seaweed. 
Table 2

Chemical analysis and monosaccharide composition of the sulfated polysaccharide obtained from G. birdiae.

\begin{tabular}{|c|c|c|c|c|c|c|c|c|c|}
\hline \multirow[t]{2}{*}{ Sample } & \multirow[t]{2}{*}{ Temp. of extraction $\left({ }^{\circ} \mathrm{C}\right)$} & \multirow[t]{2}{*}{ Weight (g) } & \multirow[t]{2}{*}{ Carbohydrate (\%) } & \multirow[t]{2}{*}{ Sulfate $^{\mathrm{a}}(\%)$} & \multirow[t]{2}{*}{ Protein (\%) } & \multicolumn{4}{|c|}{ Monosaccharide composition $^{\mathrm{b}}$ (mol\%) } \\
\hline & & & & & & AnGal & 6 Gal & 3 and 4 Gal & Gal \\
\hline $\mathrm{Gb}$ & 90 & 20.0 & 85.6 & 8.4 & 2.5 & 25.1 & 9.2 & $(\operatorname{tr})$ & 65.4 \\
\hline
\end{tabular}

in several other algae of the order Gracilariales (Melo et al., 2002; Mollet et al., 1998), and their quantities are generally variable.

In order to estimate the peak molar mass $\left(M_{\mathrm{pk}}\right)$ for $G b$ polysaccharide, a calibration was obtained using pullulan fractions. The equation obtained from the calibration plot was:

$$
M_{\mathrm{w}}=13.142-0.964 V_{\mathrm{e}}
$$

where $V_{\mathrm{e}}$ is the elution volume in $\mathrm{mL}$. The linear correlation coefficient was 0.9991.

The GPC chromatogram is shown in Fig. 1. A peak at $7.86 \mathrm{~mL}$ and a shoulder at $6.98 \mathrm{~mL}$ were detected. $G b$ polysaccharide behaves as a heterogeneous system similar to other seaweeds' polysaccharides, such as those from G. cornea (Melo et al., 2002) and Botryocladia occidentalis (Farias, Valente, Pereira, \& Mourão, 2000).

Based on Eq. (2), $G b$ polysaccharide shown $M_{\mathrm{pk}}$ values of $2.6 \times 10^{6}$ and $3.7 \times 10^{5} \mathrm{~g} \mathrm{~mol}^{-1}$, corresponding to the identified shoulder and peak. This high molar mass can be justified by grouping of polysaccharide chains, which can also be observed by the highly heterogeneous profile.

Both synthetic polymers and naturally occurring polysaccharides are polydisperse, meaning that in general they do not have sharply defined molecular weights, but rather average molecular weights representing a distribution of molecular species nearly identical in structure but of varying chain length (Stanley, 2006).

\subsection{FTIR analysis}

Table 3 shows results from FTIR analyses performed on $G b$ polysaccharide and reveals the presence of most characteristic bands of polysaccharides from red seaweeds.

The regions of the spectrum between 1400 and $700 \mathrm{~cm}^{-1}$ were expanded to better identify the positions of sulfate groups present

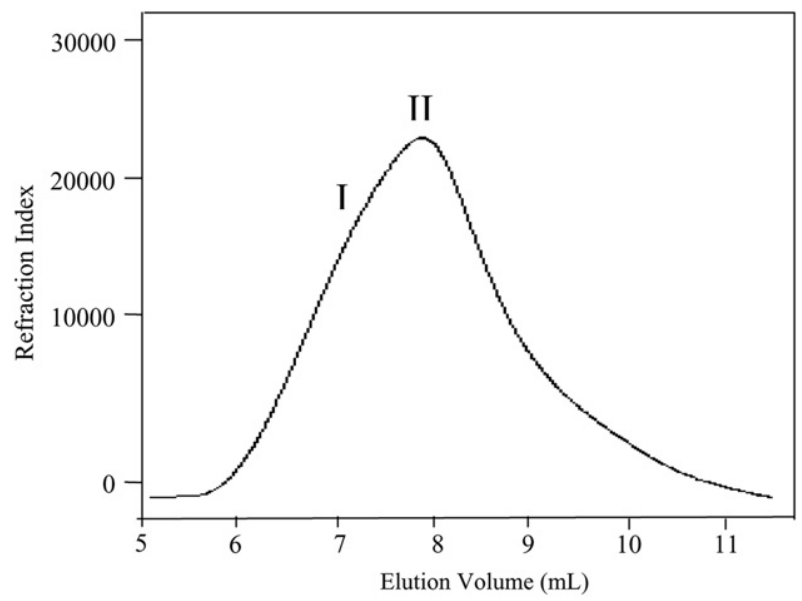

Fig. 1. GPC curve for $G$. birdiae sulfated polysaccharide. $I=$ shoulder; $I I=$ peak. in these polysaccharides (Fig. 2). The most important bands were those found at $1375 \mathrm{~cm}^{-1}$ and $1255 \mathrm{~cm}^{-1}$, corresponding to ester sulfate groups; the region around $1072 \mathrm{~cm}^{-1}$ and $890 \mathrm{~cm}^{-1}$ are equivalent to the skeleton of galactans and agar specific band, respectively. The region around $931 \mathrm{~cm}^{-1}$ can be attributed to the $\mathrm{C}-\mathrm{O}-\mathrm{C}$ group of 3,6-anhydro- $\alpha$-L-galactopyranose and the absorption around $855 \mathrm{~cm}^{-1}$ indicates the presence of sulfate groups on the C-4 of galactose. The band around $820 \mathrm{~cm}^{-1}$ is attributed to the 6-sulfate group of D-galactose units.

Studies with algae G. corticata, Gracilaria domingensis, Gracilaria mammillaris and Gracilaria pseudoverrucosa showed the presence of the band around $820 \mathrm{~cm}^{-1}$ and the absence of the band around $855-840 \mathrm{~cm}^{-1}$. However, after alkaline treatment, the infrared spectrum of the same polysaccharide registered the presence of a band around $850-840 \mathrm{~cm}^{-1}$ and no band around $820 \mathrm{~cm}^{-1}$. It was also observed that the same alkaline treatment resulted in an increase of the bands intensity around $930 \mathrm{~cm}^{-1}$. This means that the band around $820 \mathrm{~cm}^{-1}$ is related to the presence of the sulfate group at C-6 of L-galactose units, which are converted to 3,6anhydrogalactose after alkaline treatment (Mazumder et al., 2002). The residues of 6-sulfate- $\alpha$-L-galactose are known to be precursors of 3,6-anhydro- $\alpha$-L-galactose (Talarico et al., 2004).

Melo et al. (2002) also found bands at 1370 and $770 \mathrm{~cm}^{-1}$ and Maciel et al. (2008), when studying the cold extraction of G. birdiae polysaccharide, observed the same bands characteristic of agarocolloids (1375 and $775 \mathrm{~cm}^{-1}$ ).

\subsection{Rheological characterization}

The rheological behavior of $G$. birdiae sulfated polysaccharide was compared to that of commercial agar, a gel-forming polysaccharide thoroughly used by the food industry. The mechanical spectra obtained for $G b$ sulfated polysaccharide and for commercial agar at $1.5 \%(\mathrm{w} / \mathrm{w})$ and at $25^{\circ} \mathrm{C}$ are presented in Fig. 3a and b, respectively.

Both polysaccharides exhibit a gel-like behavior: storage modulus $\left(G^{\prime}\right)$ higher than loss modulus $\left(G^{\prime \prime}\right)$ in the whole range of frequencies covered and with both moduli being almost frequency independent. The mechanical spectra of the two sulfated polysaccharides are similar however, for the same concentration, the

Table 3

Assignment of the most important IR bands in agarocolloids.

\begin{tabular}{lll}
\hline Wavenumber $\left(\mathrm{cm}^{-1}\right)$ & Assignment & Reference \\
\hline $1380-1355$ & Ester sulfate $(-\mathrm{S}=\mathrm{O})$ & {$[4,5]$} \\
$1250-1240$ & $v_{\text {as }} \mathrm{S}=\mathrm{O}$ (Ester sulfate) & {$[1,4,5]$} \\
$1080-1040$ & Skeleton of galactans & {$[2,4]$} \\
$940-930$ & Vibrations of the C-O-C de & {$[1,3,4,5]$} \\
& 3,6-anhydro-L-galactose & \\
$900-890$ & Agar specific band & {$[2]$} \\
$850-845$ & Galactose 4-sulfate & {$[1,4,5]$} \\
820 & Galactose 6-sulfate & {$[2]$} \\
\hline
\end{tabular}

[1] = Chopin \& Whalen, 1993; [2] = Mollet et al., 1998; [3] = Parekh, Doshi, Rao, \& Chauhan, 1987; [4]=Prado-Fernández, Rodrígues-Vázquez, Tojo, \& Andrade, 2003; [5] = Rochas, Lahaye, \& Yaphe, 1986. 


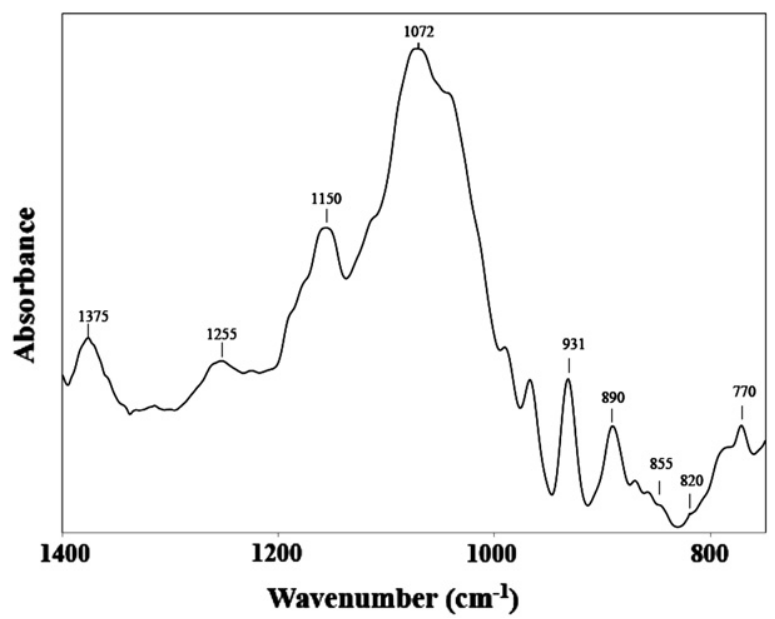

Fig. 2. FTIR spectra of sulfated polysaccharide of G. birdiae.

commercial agar solution shows a higher elastic behavior that can be due to the higher purity of the commercial sample (>95\%). Also, as expected for gels, the plot of $\left[\eta^{*}\right]$ versus $\log \omega$ was linear with a slope of -1 (Fig. 3 ).

Several authors reported that the 3,6-anhydro- $\alpha$-L-galactopyranose (AnGal) content in Gracilaria agars is an important component in the control of gel textural quality (Lahaye \& Rochas, 1991). Also, Bird, Hanisak, and Ryther (1981) observed that high gel strength of agar sample is associated with high molecular weight and larger polymers and these characteristics reflect a high capability to form 3-dimensional lattices between water and gel helices. The polysaccharide extracted in this work exhibits a solid-like behavior, that can be due to the high content in 3,6 AnGal (25.1 mol\%). Rodríguez, Matulewicz, Noseda, Ducatti, and Leonardi (2009) characterized the polysaccharides isolated from Gracilaria gracilis at three temperatures and observed that the polysaccharide
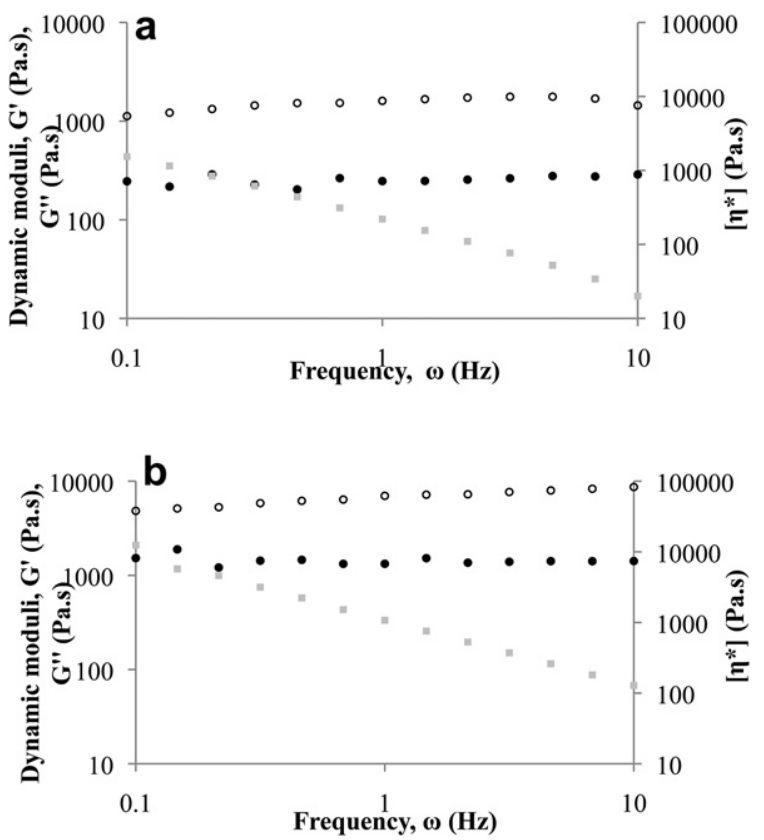

Fig. 3. Mechanical spectra of a) G. birdiae sulfated polysaccharide and b) commercial agar at a total polysaccharide concentration of $1.5 \%$, at $25^{\circ} \mathrm{C}:\left(\mathrm{G}^{\prime}(\bigcirc), \mathrm{G}^{\prime \prime}(\bullet)\right.$ and $\left.\left[\eta^{*}\right](\mathrm{O})\right)$.
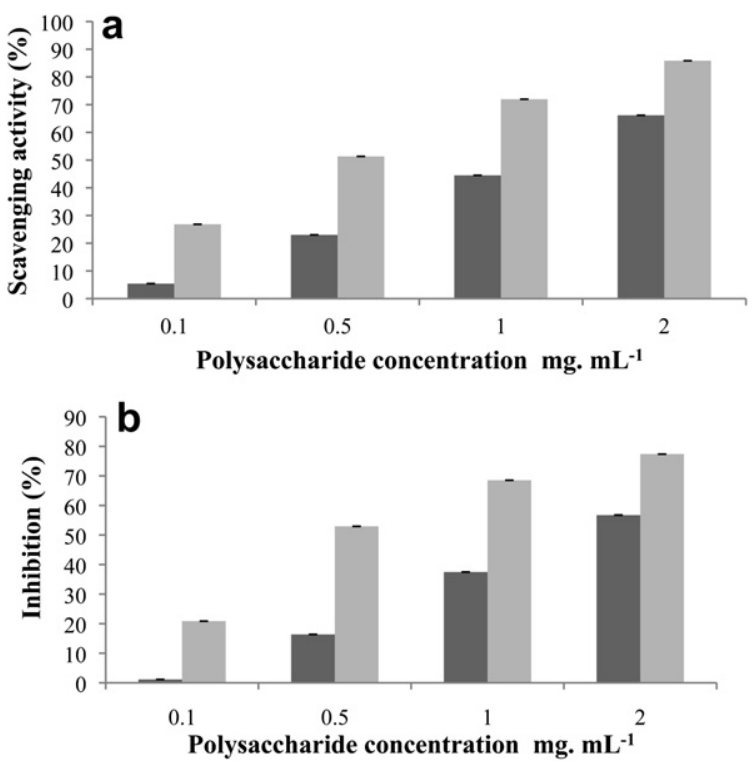

Fig. 4. Antioxidant activity: a) effect of scavenging 1,1-diphenyl-2-picrylhydrazyl (DPPH) radicals and b) Inhibition of hydroxyl radicals effects by sulfated polysaccharide of $G$. birdiae. $\square \mathrm{Gb}$; $\quad$ BHT as a positive control. Values are means \pm SD $(n=3)$.

extracted at $90{ }^{\circ} \mathrm{C}$ exhibited an 3,6 AnGal content of 35-36 mol\% and formed a gel with high strength.

\subsection{Free-radical scavenging activity}

DPPH is a free-radical compound that has been widely used to determine the free-radical scavenging ability of samples (Qi et al., 2005; Wang et al., 2009). This method allows determining the anti-radical activity of an antioxidant by measuring the decrease in absorbance of the DPPH radical caused by the scavenging of the hydroxyl radical through hydrogen donation. In this work, DPPH free-radical scavenging effect of each sample was measured (Fig. 4a). Results demonstrated that the sulfated polysaccharide had a noticeable effect on inhibiting the formation of these radicals $\left(\mathrm{IC}_{50}=1.62 \mathrm{mg} \mathrm{mL}^{-1}\right)$. However, none of the samples had stronger activity than BHT at the same concentration.

The results obtained for the inhibition of hydroxyl $\left(\mathrm{OH}^{-}\right)$radical formation demonstrated that scavenging activity of $G b$ polysaccharide increased significantly $(p<0.05)$ for higher polysaccharide concentrations. The $\mathrm{IC}_{50}$ value of $\mathrm{Gb}$ eliminating $\mathrm{OH}^{-}$ was about $1.73 \mathrm{mg} \mathrm{mL}^{-1}$, which indicates that the scavenging activity of $\mathrm{Gb}$ against $\mathrm{OH}^{-}$was less than that of BHT. Qi et al. (2005) concluded that the $\mathrm{OH}^{-}$scavenging activity of different polysaccharides was related to the presence of the same structural feature in which all of the polysaccharides had one or more $-\mathrm{OH}$ and $-\mathrm{OSO}_{3} \mathrm{H}$ groups in the molecule. These results proved that sulfate content had a significant effect on $\mathrm{OH}^{-}$scavenging activity. Souza et al. (2007) showed that iota-carrageenan had a higher inhibitory effect on $\mathrm{OH}^{-}$formation in relation to the lambda- and kappa-carrageenans. Several works have demonstrated that the presence of sulfate groups in seaweed polysaccharides is responsible for numerous types of biological activities, such as antioxidant activities (Qi et al., 2005; Wang et al., 2009).

\section{Conclusion}

The sulfated polysaccharide from marine red algae G. birdiae is composed of galactose (65.4\%) and methyl derivatives 6-O-methyl- 
galactose $(9.2 \%)$ and in smaller quantities 3-O- and 4-O-methylgalactose $(0.33 \%)$. This polysaccharide also presents a high content of 3,6-anhydrogalactose (25.1\%) and has a sulfate content of $8.4 \%$.

The sulfated polysaccharide of $G b$ characterized by FTIR exhibits the characteristic bands of agarocolloids (at 1375 and $770 \mathrm{~cm}^{-1}$ ).

It has also been shown that the $G$. birdiae sulfated polysaccharide is a promising agent to be evaluated for the application in the food industry, and that it presents a significant antioxidant activity.

\section{Acknowledgments}

The author B. W. S. Souza was recipient of a fellowship from the Coordenação de Aperfeiçoamento de Pessoal de Nível Superior (CAPES, Brazil). The authors M.A. Cerqueira, J.T. Martins and A.C. Pinheiro were recipient of fellowships from the Fundação para a Ciência e Tecnologia (FCT, Portugal) through grants SFRH/BD/ $23897 / 2005$, SFRH/BD/32566/2006 and SFRH/BD/48120/2008, respectively. The authors thank the NGO Terramar for donating the algae. Thanks are also due to the financial support of FCT to the Research Unit 62/94-QOPNA.

\section{References}

Armis, R. (1995). World-wide use and importance of Gracilaria. Journal of Applied Phycology, 7, 231-243.

Becker, C. F., Guimarães, J. A., Mourão, P. A. S., \& Verli, H. (2007). Conformation of sulfated galactan and sulfated fucan in aqueous solutions: implications to their anticoagulant activities. Journal of Molecular Graphics and Modelling, 26, 391-399.

Bird, K. T., Hanisak, M. D., \& Ryther, J. (1981). Chemical quality and production of agars extracted from Gracilaria tikvahiae grown in different nitrogen enrichment conditions. Botanica Marina, 24, 441-444.

Blois, M. S. (1958). Antioxidant determination by the use of a stable free radical. Nature, 181, 1199-1200.

Bradford, M. M. (1976). A rapid and sensitive method for the quantitation of microgram quantities of protein utilizing the principle of protein-dye binding. Analytical Biochemistry, 72, 248-254.

Cerqueira, M. A., Lima, A. M. P., Souza, B. W. S., Teixeira, J. A., Moreira, R. A., \& Vicente, A. A. (2009). Novel functional polysaccharides as edible coatings for cheese. Journal of Agricultural and Food Chemistry, 57(4), 1456-1462.

Chopin, T., \& Whalen, E. (1993). A new and rapid method for carrageenan identification by FT IR diffuse reflectance spectroscopy directly on dried, ground algal material. Carbohydrate Research, 246, 51-59.

Cote, G. L., \& Hanisak, M. D. (1986). Production and properties of native agars from Gracilaria tikvahiae and other red algae. Botanica Marina, 29, 359-366.

Dubois, M., Gillis, K. A., Hamilton, J. K., Rebers, P. A., \& Smith, F. (1956). Colorimetric method for determination of sugars and related substances. Analytical Chemistry, 28, 350-356.

Farias, W. R. L., Valente, A., Pereira, M. S., \& Mourão, P. A. S. (2000). Structure and anticoagulant activity of sulfated galactans. Isolation of a unique sulfated galactan from the red algae Botryocladia occidentalis and comparison of its anticoagulant action with that of sulfated galactans from invertebrates. Journal of Biological Chemistry, 275(38), 29299-29307.

Freile-Pelegrın, Y., \& Murano, E. (2005). Agars from three species of Gracilaria (Rhodophyta) from Yucatan Peninsula. Bioresource Technology, 96, 295-302.

Freile-Pelegrín, Y., \& Robledo, D. (1997). Influence of alkali treatment on agar from Gracilaria cornea from Yucatán, México. Journal of Applied Phycology, 9, 533-539.

F-Tischer, P. C. S., Talarico, L. B., Noseda, M. D., Guimarães, S. M. P. B., \& Duarte, M. E. R. (2006). Chemical structure and antiviral activity of carrageenans from Meristiella gelidium against herpes simplex and dengue virus. Carbohydrate Polymers, 63, 459-465.

Halliwell, B., \& Auroma, O. I. (1991). DNA damage by oxygen-derived species: its mechanism and measurements in mammalian systems. FEBS Letters, 281, 9-19.

Halliwell, B., \& Gutteridge, J. M. C. (1989). Free radicals in biology and medicine. Oxford: Oxford University Press.

Kim, S. H., Choi, D. S., Athukorala, Y., Jeon, Y. J., Senevirathne, M., \& Rha, C. K. (2007). Antioxidant activity of sulfated polysaccharides isolated from Sargassum fulvellum. Journal of Food Science and Nutrition, 12, 65-73.

Lahaye, M., \& Rochas, C. (1991). Chemical structure and physico-chemical properties of agar. Hydrobiologia, 221, 137-148.
Li, X. M. (2007). Protective effect of Lycium barbarum polysaccharides on streptozotocin-induced oxidative stress in rats. International Journal of Biological Macromolecules, 40(5), 461-465.

Lloyd, A. G., Dodgson, K. S., Price, R. G., \& Rose, F. A. I. (1961). Infrared studies on sulphate esters. I. Polysaccharide sulphates. Biochimica et Biophysica Acta, 46, 108-115.

Maciel, J. S., Chaves, L. S., Souza, B. W. S., Teixeira, D. I. A., Freitas, A. L. P., Feitosa, P. A., et al. (2008). Structural characterization of cold extracted fraction of soluble sulfated polysaccharide from red seaweed Gracilaria birdiae. Carbohydrate Polymers, 71, 559-565.

Marinho-Soriano, E. (2001). Agar polysaccharides from Gracilaria species (Rhodophyta, Gracilariaceae). Journal of Biotechnology, 89, 81-84.

Marinho-Soriano, E., \& Bourret, E. (2005). Polysaccharides from the red seaweed Gracilaria dura (Gracilariales, Rhodophyta). Bioresource Technology, 96, 379-382.

Marinho-Soriano, E., Moreira, W. S. C., \& Carneiro, M. A. A. (2006). Some aspects of the growth of Gracilaria birdiae (Gracilariales, Rhodophyta) in an estuary in northeast Brazil. Aquaculture International, 14, 327-336.

Marinho-Soriano, E., Silva, T. S. F., \& Moreira, W. S. C. (2001). Seasonal variation in the biomass and agar yield from Gracilaria cervicornis and Hydropuntia cornea from Brazil. Bioresource Tecnnology, 77, 115-120.

Mazumder, S., Ghosal, P. K., Pujol, C. A., Carlucco, M. J., Damonte, E. B., \& Ray, B. (2002). Isolation, chemical investigation and antiviral activity of polysaccharides from Gracilaria corticata (Gracilariaceae, Rhodophyta). International Journal of Biological Macromolecules, 31, 87-95.

Melo, M. R. S., Feitosa, J. P. A., Freitas, A. L. P., \& de Paula, R. C. M. (2002). Isolation and characterization of soluble sulfated polysaccharide from the red seaweed Gracilaria cornea. Carbohydrate Polymers, 49, 491-498.

Mollet, J. C., Rahaoui, A., \& Lemoine, Y. (1998). Yield, chemical composition and gel strength of agarocolloids of Gracilaria gracilis, Gracilariopsis longissima and the newly reported Gracilaria cf. vermiculophylla from Roscoff (Brittany, France). Journal of Applied Phycology, 10, 59-66.

Parekh, R. G., Doshi, Y. A., Rao, V. D., \& Chauhan, V. D. (1987). Studies on a phycocolloid from red alga Halymenia venusta Boergesen. Indian Journal of Marine Sciences, 16, 274-276.

Plastino, E. M., Ursi, S., \& Fujii, M. T. (2004). Color inheritance, pigment characterization, and growth of a rare light green strain of Gracilaria birdiae (Gracilariales, Rhodophyta). Phycological Research, 52, 45-52.

Prado-Fernández, J., Rodrígues-Vázquez, J. A., Tojo, E., \& Andrade, J. M. (2003). Quantitation of $\kappa-, \mathrm{l}-$ and $\lambda$-carrageenans by mid-infrared spectroscopy and PLS regression. Analytica Chimica Acta, 480, 23-37.

Qi, H., Zhao, T., Zhang, Q., Li, Z., \& Zhao, Z. (2005). Antioxidant activity of different molecular weight sulfated polysaccharides from Ulva pertusa Kjellm (Chlorophyta). Journal of Applied Phycology, 17, 527-534.

Rees, D. A. (1961). Biogenesis of 3-6-anhydro-L-galactose. Biochemical Journal, 81, 347-352.

Rochas, C., Lahaye, M., \& Yaphe, W. (1986). Sulfate content of carrageenan and agar determined by infrared spectroscopy. Botanica Marina, 29, 335-340.

Rodríguez, M. C., Matulewicz, M. C., Noseda, M. D., Ducatti, D. R. Z., \& Leonardi, P. I. (2009). Agar from Gracilaria gracilis (Gracilariales, Rhodophyta) of the Patagonic coast of Argentina - content, structure and physical properties. Bioresource Technology, 100, 1435-1441.

Smirnoff, N., \& Cumbes, Q. J. (1989). Hydroxyl radical scavenging activity of compatible solutes. Phytochemistry, 28, 1057-1060.

Souza, M. C. R., Marques, C. T., Dore, C. M. G., Silva, F. R. F., Rocha, H. A. O., \& Leite, E. L. (2007). Antioxidant activities of sulfated polysaccharides from brown and red seaweeds. Journal of Applied Phycology, 19, 153-160.

Stanley, N. F. (2006). Agars. In A. M. Stephen, G. O. Phillips, \& P. A. Williams (Eds.) Food polysaccharides and their applications (2nd ed.). CRC/Taylor \& Francis.

Stevenson, T. T., \& Furneaux, R. H. (1991). Chemical methods for the analysis of sulphated galactans from red algae. Carbohydrate Research, 210, 277-298.

Talarico, L. B., Zibetti, R. G. M., Faría, P. C. S., Scolaro, L. A., Duarte, M. E. R., Noseda, M. D., et al. (2004). Anti-herpes simplex virus activity of sulfated galactans from the red seaweeds Gymnogongrus griffithsiae and Cryptonemia crenulata. International Journal of Biological Macromolecules, 34, 63-71.

Troell, M., Halling, C., Neori, A., Chopin, T., Buschmann, A. H., Kautsky, N., et al. (2003). Integrated mariculture: asking the right questions. Aquaculture, 226 69-90.

Wang, J., Zhang, Q., Zhang, Z., Zhang, J., \& Li, P. (2009). Synthesized phosphorylated and aminated derivatives of fucoidan and their potential antioxidant activity in vitro. International Journal of Biological Macromolecules, 44(2), 170-174.

Yang, Y. F., Fei, X. G., Song, J. M., Hu, H. Y., Wang, G. C., \& Chung, I. K. (2006). Growth of Gracilaria lemaneiformis under different cultivation conditions and its effects on nutrient removal in Chinese coastal waters. Aquaculture, 254, 248-255.

Ye, H., Wang, K., Zhou, C., Liu, J., \& Zeng, X. (2008). Purification, antitumor and antioxidant activities in vitro of polysaccharides from the brown seaweed Sargassum pallidum. Food Chemistry, 111, 428-432. 